\title{
Effects of Agile Practices on Social Factors
}

\author{
Amy Law \\ TransCanada \\ $450-1^{\text {st }}$ Street S.W. \\ Calgary, Alberta, T2P 4K5, Canada \\ 403-920-6049 \\ amy_law@transcanada.com
}

\author{
Raylene Charron \\ TransCanada \\ $450-1^{\text {st }}$ Street S.W. \\ Calgary, Alberta, T2P 4K5, Canada \\ 403-920-5209
}

raylene_charron@transcanada.com

\begin{abstract}
Programmers are living in an age of accelerated change. State of the art technology that was employed to facilitate projects a few years ago are typically obsolete today. Presently, there are requirements for higher quality software with less tolerance for errors, produced in compressed timelines with fewer people. Therefore, project success is more elusive than ever and is contingent upon many key aspects. One of the most crucial aspects is social factors. These social factors, such as knowledge sharing, motivation, and customer collaboration, can be addressed through agile practices. This paper will demonstrate two successful industrial software projects which are different in all aspects; however, both still apply agile practices to address social factors. The readers will see how agile practices in both projects were adapted to fit each unique team environment. The paper will also provide lessons learned and recommendations based on retrospective reviews and observations. These recommendations can lead to an improved chance of success in a software development project.
\end{abstract}

\section{Categories and Subject Descriptors}

D.2.9 [Software Engineering]: Management - Software process models (agile practices).

\section{Keywords}

Keywords of this paper are social factors, knowledge sharing, motivation, customer collaboration, and agile practices.

\section{INTRODUCTION}

TransCanada is a leading North American energy company. The TransCanada network consists of approximately 41,000 kilometers (25,600 miles) of pipeline, which transports most of Western Canada's natural gas production to growing markets in Canada and the United States. TransCanada also owns, controls or is constructing more than 5,100 megawatts of power generation capacity. To support this enterprise, the IS department has delivered many software solutions for specific business needs.

\footnotetext{
Permission to make digital or hard copies of all or part of this work for personal or classroom use is granted without fee provided that copies are not made or distributed for profit or commercial advantage, and that copies bear this notice and the full citation on the first page. To copy otherwise, to republish, to post on servers or to redistribute to lists, requires prior specific permission and/or a fee.
}

Human and Social Factors of Software Engineering (HSSE) May 16, 2005, St. Louis, Missouri, USA

Copyright 2005 ACM ISBN \# 1-59593-120-1/05/05.
Two of the software solutions were Project $\mathrm{X}$ and Project $\mathrm{Y}^{1}$. These projects were different in system requirements, customer base, programming team, budget, and timeline. As shown in Table 1, Project X and Project Y were developed by two different teams. The Project $X$ team had twelve full-time programmers who were dedicated to Project X. Alternatively, the Project Y team had six programmers who were not exclusively working on one project and they wore many hats during the course of software development. The Project $\mathrm{X}$ system served only one user community and was implemented in Java programming language. On the other hand, the Project Y system served two different user communities and was implemented in a combination of Java programming language and Forte Conductor $^{2}$.

Table 1. Summary of Project $X$ and Project $Y$

\begin{tabular}{|l|r|r|}
\hline & Project X & \multicolumn{1}{|c|}{ Project Y } \\
\hline Type & New & Enhancement \\
\hline Number of Programmers & 12 & 6 \\
\hline Programmer Dedication & Full Time & Part Time \\
\hline Duration & 3 years & 8 months \\
\hline Delivery Date & July 2004 & February 2005 \\
\hline Technology & Java & Java \& Forte \\
\hline Number of User Groups & 1 & 2 \\
\hline
\end{tabular}

With varying degrees, both of these software teams applied agile practices to address social factors such as increased knowledge sharing, motivation, and customer collaboration.

Knowledge is what people accumulate in the process of learning and gathering experiences. Not only does knowledge help people solve problems, but it also helps people adapt and improve in their unique environment. Personnel turnover can sometimes lead to the loss of vital knowledge, result in a steep learning curve, and impact project delivery. To mitigate this risk, knowledge sharing

\footnotetext{
${ }^{1}$ Project $\mathrm{X}$ and Project $\mathrm{Y}$ are real software development projects in TransCanada. Their real names are not revealed due to confidentiality.

${ }^{2}$ Forte Conductor is a development tool under Sun Microsystems. It can be used to define the flow of business processes and decompose them into subprocess workflows.
} 
is required. Conventional software development projects (nonagile projects) have limited interaction between programmers and do not promote knowledge sharing on a day-to-day basis. The question becomes how do you enable knowledge sharing in a team?

Motivation is the source to performance improvement which leads to productivity gain. The key to productivity is an integrated workforce [3]. In an integrated workforce, people act selflessly and contribute to the greater good which makes the team more than the sum of its parts. This results in a harmonious environment and the joy of working in harmony is a powerful motivating force [12]. In traditional software development, the approach tends to be more "divide and conquer" rather than working as a team to deliver a common goal. The challenge is how to create harmony amongst your programmers, business analysts, and customers, and motivate them to greater productivity?

The nature of a software development project is that it cannot be done by any single person in isolation. Instead, it is a collaborative effort among people in a team and between teams. The team helps to align goals, keeps all members pulling in the same direction, and promotes a sense of community [10]. In promoting a higher level of teamwork, customer collaboration also has to be promoted. Traditional software development methods use top-down management and customer feedback comes slowly at the end. The question becomes how to effectively collaborate with your customers throughout the course of software development?

This paper will focus on how agile practices address social factors and their relationship in two successful industrial software projects developed at TransCanada. It will provide analysis on retrospective reviews and make recommendations addressing the questions posed above.

\section{KNOWLEDGE SHARING}

How do you enable knowledge sharing in a team? It is not easy to promote knowledge sharing in the environment of traditional software development projects. Fortunately, people have a natural affinity to learn and gather knowledge [10]. Therefore, the application of four agile practices [1], including pair programming, co-location, daily status meeting, and minimal documentation, came naturally to the Project $\mathrm{X}$ and Project $\mathrm{Y}$ programming teams. Some examples of these practices follow:

\subsection{Pair Programming}

The Project $\mathrm{X}$ programmers applied pair programming practice on a daily basis. The benefits were realized when new programmers were able to produce and check in finished code on the first day of work. This made meaningful contributions to the team. Another benefit realized was a reduced initial learning curve.

The Project Y programmers, however, applied pair programming mostly under two conditions. Pair programming was used with experienced members when working with leading edge technology and when new programmers joined the team. Since the programmers were involved in multiple projects, they could not always align their work schedule for pairing. As an alternative, individual programmers applied code inspection prior to checking in code changes. Another programmer in the team would inspect the source code to look for programming errors.
The combination of pair programming and code inspection enabled knowledge sharing and cross training between programmers.

\subsection{Co-location}

The idea of co-location is to physically move the whole team into a common area. As shown in Figure 1, the Project $\mathrm{X}$ team was co-located with the customer leader in an open environment. This seating arrangement facilitated effective face-to-face interaction and knowledge sharing. Some people did not like this openness due to their desire for personal space and privacy.

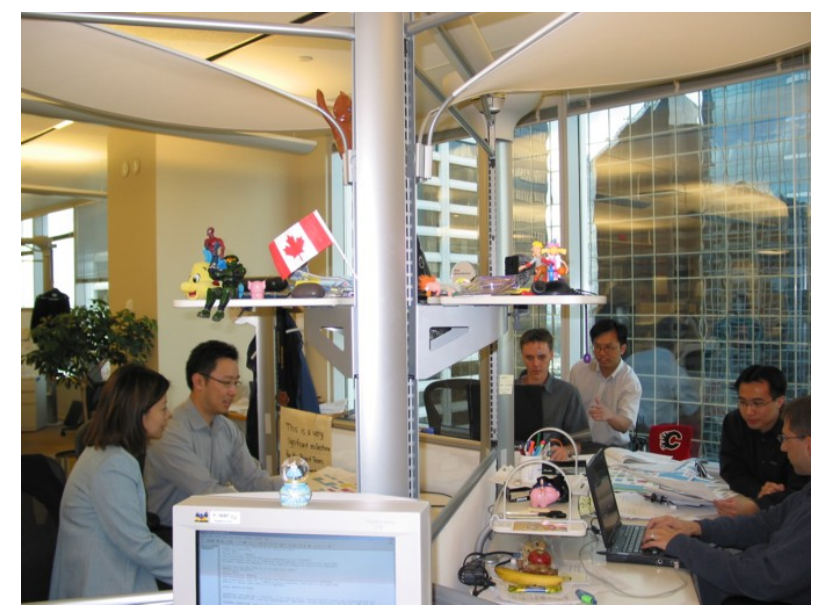

Figure 1. Open Environment

The Project $\mathrm{Y}$ team was also co-located in a common cubical zone, as shown in Figure 2. This area was known as the "Bullpen". This seating arrangement was perfect for promoting team interactions such as asking and answering quick questions. This close proximity also promoted spontaneous discussion. With the partition, personal space and privacy were guaranteed.

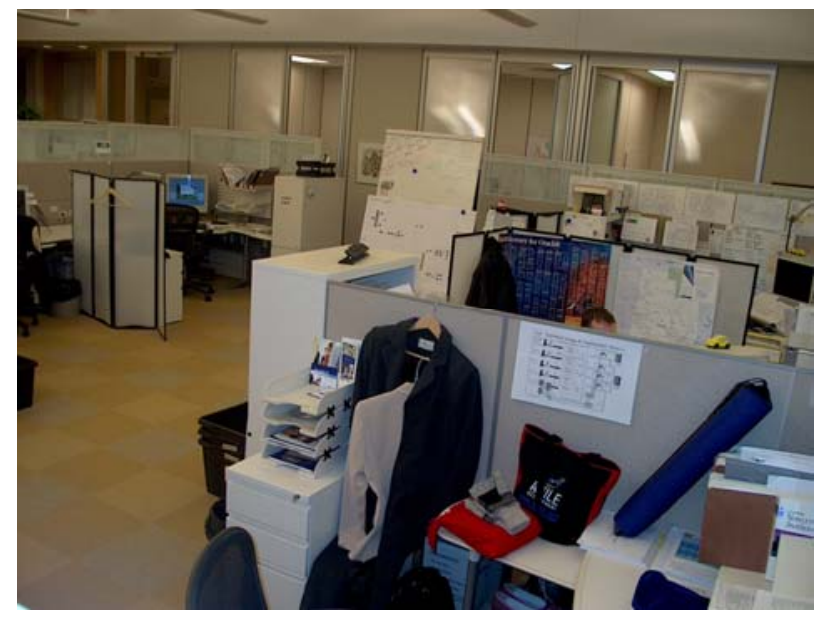

Figure 2. "Bullpen”

\subsection{Daily Status Meeting}

Another agile technique, adopted to enable ongoing knowledge sharing, was the daily scrum meeting. The Project X moved the daily meeting time to accommodate scheduling conflicts, and encourage all of the programmers, business analysts and customer leader to attend the meeting. 
As a variation to the daily scrum meeting concept, the Project $\mathrm{Y}$ leader gathered regular updates from the programmers. This informal meeting could happen any time in a day. As per schedule, the Project Y leader and customer leader met daily to go over the project progress and impediments. When required, the programmers joined the meeting to discuss requirements and demonstrate the latest features. Since the programmers had many roles, they had to shift their focus between Project Y and other operational and maintenance projects several times a day. Therefore, it would not be effective for all the programmers to be included in the daily meeting. At any time, the programmers were free to set up their own meeting with the customer leader to clarify requirements. This promoted communication and quick decision-making without hindering efficiency.

\subsection{Minimal Documentation}

Although agile practices emphasize working software over comprehensive documentation [9], minimal or "just enough" documentation is encouraged. At the beginning of each sprint, the Project $\mathrm{X}$ team wrote white papers describing system requirements and test cases. Occasionally, the requirements, such as validation logics and user interface, changed to fine tune usability. The white papers were used to capture complicated concepts and to effectively kick-start discussions. They were not kept up to date. At the conclusion of the project, the team collaboratively updated the documents to avoid the "one webmaster syndrome”. This syndrome makes one programmer responsible to write the entire manual. To avoid the syndrome, the team created a $\mathrm{Wiki}^{3}$ web site. The programmers collaboratively added project information in the web site.

On the other hand, the Project Y team created a Wiki web site at the beginning of the project. This web site housed the documentation concerning project requirements, system design, monthly project status reports and user acceptance test plans. It became the central hub for project knowledge. The Project $\mathrm{Y}$ team created screen mockups to represent system requirements. As "a picture is worth a thousand words", the documentation was more visual than textual. Therefore, the documentation had shorter description and more detailed. The quick publishing ability of Wiki also kept the documentation more up-to-date.

\section{MOTIVATION}

Assuming knowledge sharing has been successfully achieved, the next challenge becomes how to motivate the programmers? Motivation has the single largest influence on quality and productivity than any other factor in software development [4].

\subsection{Learning}

Since people have a natural affinity for learning, an environment in which learning opportunities exist can be a highly effective motivator. Programmers new to Project $\mathrm{X}$ were unfamiliar with the system. Pair programming allowed them to make meaningful contributions on the first day. Similarly, the experienced programmers had an opportunity to coach others and develop sound communication skills.

\footnotetext{
${ }^{3}$ Wiki is a server software to create and maintain web page contents. It supports hyperlinks and cross links between pages.
}

As a complement to pair programming, Project $\mathrm{Y}$ team applied code inspection. This allowed the new programmers to reap the benefits of both practices and increase productivity over independent learning.

\subsection{Autonomy}

Another motivating element was to provide autonomy to programmers. The Project $\mathrm{X}$ team was able to achieve this goal. After the customer leader prioritized system requirements, the programmers had the power to add new tasks to fulfill the system requirements. In a way, the customer leader made business decisions, whereas the programmers made technical decisions. This is the basis for project management where the power between the customers and the programmers is balanced [9]. On the other hand, the autonomy was limited in Project $\mathrm{Y}$ due to the inadequate resources. The team was restricted to a predefined approach such that programming tasks were already identified. The Project Y team was motivated by other external stimulus than autonomy.

\subsection{Social Activities}

Social activities foster interpersonal relationships and increase the familiarity amongst team members. The Project $\mathrm{X}$ team organized birthday lunches. An occasional afternoon bubble tea break or chocolates, candies, and toys were made available. As a result, the programmers felt cared for.

In parallel, Project $\mathrm{Y}$ had similar team building activities. The "greater" team ${ }^{4}$ organized Friday breakfasts. The team enjoyed breakfast and chatted about their personal lives. These social interactions manifested themselves. The employees were motivated by the concern for their well being.

\section{CUSTOMER COLLABORATION}

In a survey of 8,000 projects, the number one cause of project failure was a lack of user involvement [5]. Given these statistics, the question becomes how to effectively collaborate with your customers?

\subsection{Delivery Strategy}

There are many delivery strategies targeted to fulfill different system requirements. In the past, customers would not see the software until it was close to production. This was known as the "Big Bang Delivery". This approach reduced early customer intervention and impacted the success of a project.

As an alternative to the "Big Bang Delivery", the Project $\mathrm{X}$ and Project $\mathrm{Y}$ teams adopted small releases delivery strategy. Both teams deployed new features to production on a monthly basis. In this approach, the customers were involved up front. They could see, touch, and feel the working software as soon as the new features were ready. Any error could be rectified immediately.

\subsection{Monthly Sprint Review Meeting}

The Project $\mathrm{X}$ team and Project $\mathrm{Y}$ team held monthly sprint review to discuss project progress, budget forecasts, requirement changes, deviations in estimates and potential risks.

\footnotetext{
4 The "greater" team consists of Project Y team and other operational and maintenance project teams in the same department.
} 
As Project $\mathrm{Y}$ system was implemented for two business departments, customers representing these departments would participate in the review sessions. This enabled frequent user involvement and communication among different business departments. It kept the development process transparent with no secrets. However, there were issues with competing priorities between the two user groups. For example, the user group I required to impose a two-month code freeze for the operational and maintenance project. However, the user group II required the implementation to achieve the benefits of Project $\mathrm{Y}$ within the committed timeline. Through proper communication and negotiation, it was decided to execute the code freeze unless there was a major break fix requirement during the freeze.

\subsection{Different Perspectives on Software}

While evaluating a system, customers might consider the response time and user interface functionality as a measure of software quality. On the other hand, programmers might consider code readability and reusability as their measure of software quality. Fundamentally, customers and programmers have conflicting views on what constitutes software quality. Traditionally, customers and programmers lack opportunities for communication. In some cases, the requirements are drafted by a business analyst. This can lead to miscommunications of requirement between the customers and programmers. Without proper collaboration, problems will arise in software development as the feature set has not been properly communicated.

The Project $\mathrm{X}$ business leader was co-located with the programming team in an open environment. Similarly, one of the Project Y leaders was on site in the same office building, whereas the other Project Y leader was co-located with the programming team on the same floor. The close proximity of customers and programmers fostered open communications. Both project teams applied daily status meeting, monthly sprint review meeting, and small releases. These ongoing communications allowed the programmers to anticipate the customers' needs. The customers learned to appreciate the programmers' efforts in producing the timely features required. This created a win-win situation.

\section{REFLECTION}

Project $\mathrm{X}$ and Project $\mathrm{Y}$ are different projects. With varying degrees, both teams implemented agile practices with modifications to fit into their unique environments. Project $\mathrm{X}$ can be viewed as a brand new software development project, whereas Project $\mathrm{Y}$ can be viewed as a sustain project with various enhancements. Specifically, the sustain project had operational requirements with higher priority than enhancement requirements. Both project teams addressed social factors by adopting agile practices. These factors are driven by common sense; however, the question becomes how people interact, what affects their performance, and how to harness human potential to maximize project success. The project teams completed retrospective reviews concluding with the following observations.

\subsection{Knowledge Sharing}

Knowledge sharing was achieved through the application of agile practices such as: pair programming, co-location, daily status meetings, and minimal documentation. However, the application of these practices does not always come easily and some discipline is required to reap the full benefits of these practices.
Pair programming can blend expertise of programmers. However, in Project $\mathrm{X}$, the benefits of pair programming were tempered, where the pairs stayed together for several consecutive sprints. Knowledge sharing was not distributed throughout the team, but was limited to pairs. In addition, passive programmers tend to lose their motivation in the pairing activities, as the dominant programmer tends to dictate the path for the development.

In Project $\mathrm{Y}$, the benefits of pairing were also tempered by scheduling conflicts and multi-tasking. Pair programming in this work environment was not always possible and did not fully promote knowledge sharing. Time-sharing penalties arose, while attempting to perform a number of tasks concurrently. The context switching of a dedicated worker to multiple tasks could lead to a loss of up to six hours per week or more of productivity, and the loss of productivity is greater when the partitioning is greater [10]. Typically, operational requirements have higher priority than enhancement requirements in a sustain project. The programmers need to respond and resolve the issue before the deadline. If the solution did not come on a timely fashion, the team performance evaluation would be impacted according to the service level agreement. As a result, the paired programmers tended to focus of separate tasks, which addressed their own individual deadlines. Since both parties were not dedicating themselves to the common goal related to the original pair programming project, the productivity and schedule would suffer, as a result. Therefore, the project manager needs to understand resource planning prior to committing to pair programming.

Daily status meeting enabled the Project $\mathrm{X}$ programmers to understand project progress and overcome impediments as a team. Sometimes, questions raised in daily status meeting could be resolved quickly because everyone contributed to solving the problems. Multiple solutions could be derived. As a positive side effect, direct communication and timely assistance to others strengthen team relationships. Alternatively, in Project $\mathrm{Y}$, not every programmer attended the daily status meeting due to conflicting schedules. The team used the minimal documentation approach, Wiki web site, as a central hub of knowledge sharing and orientation materials. This is especially useful and effective when turnover rate was high.

The Wiki web site syntax was not user friendly to some of the customers. The lack of usability became a knowledge sharing barrier to customers who wanted to edit or add document to the web site. Customer knowledge sharing could be improved by using a collaboration tool which is familiar to customers. One potential collaboration tool would be Microsoft SharePoint tool which has a similar look and feel to the Microsoft Office Suite.

An open environment and bullpen are two types of co-location strategies used at TransCanada. Both seating arrangements worked well to promote frequent communication. However, the open environment typically works more effectively for people with extroverted personality. On the other hand, the bullpen is usually more suitable to those who highly value privacy. This is the result of diverse cultures. By understanding and accepting this diversity, people could work in harmony to achieve their common goals. In conclusion, the open environment can maximize human communication; however, some people cannot weigh it over their desire to personal space and privacy. Before adopting a co-location strategy, project teams need to understand their culture and adjust their environment accordingly. 


\subsection{Motivation}

Pair programming and code inspection provided learning opportunities which contributed to motivation. However, pairing could have a negative impact if pairs have personality conflicts. In order to ensure pair programming has a positive influence on all pairs, the whole team has to make accommodations for each other's idiosyncrasies. Programmers should tune their behaviors to promote a team environment.

In some cases, the pairing concept is crucial to a sustain project where support tasks are fragmented and team members are responsible to resolve operational issues within an agreed timeframe. Under this condition, pairing is a motivating factor to combine knowledge and to quickly resolve a sustain issue in order to deliver an effective solution. Timely assistance to others can strengthen team relationships.

Autonomy was a motivating factor to encourage programmers to select the challenging tasks that they enjoy. However, there are tasks that must be completed and yet did not provide a learning ground. It is important to strike a balance between the autonomy and project delivery. As in a sustain project, programmers are motivated to resolve the operational issues to meet the individual deadlines and to help each other to meet the common goals as defined in the service level agreement.

\subsection{Customer Collaboration}

The shift from the traditional "Big Bang Delivery" approach to small releases, monthly sprint review meetings and ongoing communications facilitated customer collaboration. Similar to knowledge sharing, these practices require adaptation and some discipline is required to reap the full benefits.

Project $\mathrm{X}$ provided scrum training to programmers, business analysts, and customers at the beginning of the project. As a result, the team understood the methodology. With programmers, business analysts, and customers in a class together, this provided project members a sense of community to learn a software development process. This also gave the opportunity to start adapting to the new process as a team.

Small releases allowed users to learn the new features incrementally, understand the realistic project progress, and provide feedback on an iterative basis. However, this approach required customers to perform user acceptance testing a lot more frequently than the conventional software development. This required cooperation and a time commitment from customers. The initial scrum training encouraged the Project $\mathrm{X}$ customers to buy in. Project Y, on the other hand, was an enhancement project. All of its features were bundled with operational and maintenance changes. Typically, operational requirements came from customers on a regular basis. Therefore, small releases were already customary to customers.

The Project $\mathrm{X}$ team met monthly with management and customers to review the previous sprint results. The team learned that the most effective demo was the one delivered by the customer speaking in the business language. Monthly demos in Project Y created kick start talking points for customers from different departments to collaboratively discuss and finalize their requirements prior to deployment. These demos provided the initial exposure to the new software for the customers who would later perform user acceptance tests. Without the initial exposure, it would be more challenging for the customers to become familiar and comfortable with the software product.

\section{CONCLUSION}

There is no silver bullet that always leads to software development success [7]. This is especially true in today's rapidly changing technology environment. However, there are some solid theories and case studies, which can contribute to a project's success. As the industrial cases showed, the programmers take pride in their work by developing timely software. The customers want timely systems which are usable and economical. Both parties require the humanistic approach promoted through the use of agile practices. The programmers and customers help each other through collaboration, knowledge sharing, and motivation to achieve their intertwined goals. By addressing these social factors, a project team has an improved chance of success in a software development project.

\section{ACKNOWLEDGMENTS}

We would like to thank Jim Nicholas, Claudio Perrella, Rick Coutts, Lynne Ralston, Laurie Shafer, Jennitta Andrea, Allen Ho, Stan Wong, Jeff Lamey, Mike Lippold, Bruce Huynh, Dave Chiste, Tam Nguyen, and the agile community for their guidelines and encouragement.

\section{REFERENCES}

[1] Beck, Kent, 2000, "Extreme Programming Explained" Addison Wesley Professional, p 116-117.

[2] Poppendieck, Mary, Poppendieck, Tom, 2003, "Lean Software Development - An Agile Toolkit”, Addison Wesley, p 15-25.

[3] Blanchard, Kenneth, Johnson, Spencer, 1982, "The One Minute Manager”, HarperCollins Business.

[4] Boehm, Barry, 1981, "Software Engineering Economics”, Prentice-Hall.

[5] The Standish Group, 1994, “The CHAOS Report (1994)”. http://www.standishgroup.com/sample_research/chaos_1994 1.php

[6] DeMarco, Tom, Lister, Timothy, 2003 "Waltzing with Bears, Managing Risk on Software Projects", Dorset House Publishing.

[7] Brooks, Frederick P. 1995, “The Mythical Man-Month Essays on Software Engineering”, Addison-Wesley Publishing Company, p 178-203.

[8] Schwaber, Ken, Beedle, Mike, 2002, “Agile Software Development with Scrum - Series in Agile Software Development”, Prentice Hall.

[9] Agile Manifesto, 2001, "Manifesto for Agile Software Development”, http://www.agilemanifesto.org/

[10] DeMarco, Tom, 2001, “Slack”, Broadway Book.

[11] DeMarco, Tom, Lister, Timothy, 1999, "Peopleware Productive Projects and Teams”, Dorset House Publishing Company, p 119-120, 160, 230.

[12] Jackson, Phil, 1995, “Sacred Hoops”, Hyperion New York. 